\title{
O jardim sem limites, de Lídia Jorge - ou, por outras palavras, a situação do Portugal pós-25 de abril
}

O jardim sem limites, by Lídia Jorge - or, in other words, the situation in Portugal after April 25th

Luara Pinto Minuzzi ${ }^{1}$

Doutoranda em Teoria da Literatura pela PUCRS e mestra em Teoria da Literatura tambèm pela PUCRS. Bolsista CNPq.
RESUMO: Este trabalho tem por objetivo pensar o livro 0 jardim sem limites, da escritora Lídia Jorge, como uma alegoria da situação de Portugal após a Revolução dos Cravos: o microcosmo Casa da Arara, onde os personagens do romance habitam, representaria o macrocosmo Portugal, assim como os habitantes do primeiro e do segundo andar e a tensão entre esses dois níveis, corresponderiam às diferentes gerações que compõem o povo português. Dessa forma, o cotidiano conflituoso em que convivem os moradores mais jovens do segundo piso e os mais velhos do primeiro seria a representação do distanciamento entre uma geração que viveu o salazarismo e que combateu o regime e outra que nasceu após o fim do totalitarismo e que não compreende os sacrifícios realizados pelos primeiros a fim de que todos pudessem usufruir da liberdade. Para tal análise, foram utilizados, como fundamentação teórica, estudos de filósofos que pensam a nação lusa, sua identidade e história, como Eduardo Lourenço, Boaventura de Sousa Santos e Jorge Babo.

PaLAVRAS-CHAVE: Revolução dos cravos; Choque de geraç̃es; Lídia Jorge; 0 jardim sem limites.

ABSTRACT: This study aims to think the book 0 jardim sem limites, by Lydia Jorge, as an allegory of the situation of Portugal after the Carnation Revolution: the microcosm Casa da Arara, where the novel's characters inhabit, represents the macrocosm Portugal, as well as the inhabitants of the first and second floor and the tension between these two levels correspond to different generations that make up the Portuguese people. Thus, the conflicted everyday who live in the younger residents of the second floor and the older of the first would be the representation of the distance between a generation that lived the Salazar era and fought the regime and another that was born after the end of totalitarianism and does not understand the sacrifices made by the first group so that everyone could enjoy freedom. For this analysis, it was used as theoretical foundation studies by philosophers who think the Portuguese nation, its identity and history, as Eduardo Lourenço, Boaventura de Sousa Santos and Jorge Babo. KEYwORDS: Carnation Revolution; Clash of generations; Lídia Jorge; O jardim sem limites. 
Não sei, meus filhos, que mundo será o vosso.

É possível, porque tudo é possível, que ele seja aquele que eu desejo para vós. Um simples mundo, onde tudo tenha apenas a dificuldade que advém

de nada haver que não seja simples e natural.

Um mundo em que tudo seja permitido,

conforme o vosso gosto, o vosso anseio, o vosso prazer, o vosso respeito pelos outros, o respeito dos outros por vós.

E é possível que não seja isto, nem seja sequer isto o que vos interesse para viver. (SENA, 2014)

"O u por outras palavras" - essa é a oração com a qual a obra da escritora portuguesa Lídia Jorge, 0 jardim sem limites, é aberta. Nada vem antes, a fim de sabermos quais são as primeiras palavras que serão substituídas por essas outras trazidas pela narrativa - ou tudo vem antes: todo o discurso, a história e o conhecimento de e sobre um Portugal que passou por uma revolução a fim de derrubar um regime ditatorial que ficou no poder por nada menos do que 48 anos e que acabara de entrar para a Comunidade Europeia e de abrir suas portas para o mundo já em plena era da globalização. Assim, o leitor depara-se com a história de alguns jovens que, no final dos anos 1980, sonham em bater o record da imobilidade voluntária e que leem jornais do dia anterior a fim de nunca conseguirem olhar em tempo as ofertas de empregos. Também com a de homens que participaram ativamente da Revolução dos Cravos e que agora foram esquecidos e são encorajados a também esquecer o passado com o propósito de participarem de forma mais efetiva dessa sociedade que visa ao lucro acima de tudo ou, por outras palavras, o leitor encontra, no sexto romance publicado por Lídia Jorge, em 1995, o retrato de um Portugal essencialmente voltado para fora, para a cultura produzida no exterior e olvidado de sua própria história.
Sobre isso, a narradora do romance, de quem não conhecemos o nome, comenta: "Não é correcto dizer-se que nos trancámos, ignorando o que se passava no exterior da Casa da Arara. Bem pelo contrário. Mantenho a ideia de que, por força das circunstâncias, nos íamos transformando em uma espécie de higrómetro, diante do cais" (JORGE, 1995, p. 31). Higrômetro é um instrumento utilizado com o intuito de medir a umidade da atmosfera do ar, da mesma forma como os personagens principais da narrativa medem as condições do clima da terra lusitana nesse momento histórico - o que é esclarecido ainda pela narradora: "Como já disse, apenas me interessava o espetáculo do mundo, e a partir da Casa da Arara, eu tinha a ideia de que o via na totalidade, espelhado numa gota de água" (JORGE, 1995, p. 51). Assim sendo, tal obra pode ser vista como uma alegoria dessa época do país localizado na ponta da Europa e é justamente o objetivo do presente artigo desenvolver uma análise que comprove essa ideia.

Portanto, faz-se importante apresentar tais personagens-símbolos da condição portuguesa desse tempo, tais gotas de água nas quais toda uma sociedade encontra-se espelhada. Em primeiro lugar, surge a narradora, sobre quem praticamente não há informações - sabemos que ela decidiu alugar um quarto da casa da Arara, na Rua da Tabaqueira, pois sentiu que poderia fazer o barulho que desejasse batendo as teclas da sua Remington e escrever o esquema de suas histórias nas paredes sem que houvesse quaisquer reclamações; sabemos, além disso, que ela é uma jovem escritora. E é só. Essa narradora posiciona-se como uma observadora que não interfere nas ações dos personagens observados: "Eu apenas me limitava a registrar" (JORGE, 1995, p. 173); "Que fique claro que nunca escrevi - Não se inquietem, não busquem, não interroguem. Também nunca disse o contrário" (ibid., p. 331). Porém, é a ela que os personagens, em momentos diferentes da narrativa, recorrem para confidências e reflexões - o que faz com que a narradora seja uma espectadora privilegiada de duas gerações diferentes, 
representadas pelas pessoas que habitam o térreo e o segundo andar da casa.

No segundo andar, vivem seis jovens (além da própria escritora) que alugam quartos: Paulina, Leonardo, Falcão, César, Osvaldo e Gamito - e todos, menos a moça, assemelham-se a artistas e produtores de cinema norte-americanos: Leonardo parece com Jack Nicholson, na cena em que o personagem conduz um barco em Um estranho no ninho; já Falcão, com Orson Welles; César lembra Dustin Hoffman; Gamito, Burt Lancaster e Osvaldo, Al Pacino. Além disso, eles usam constantemente termos em inglês, como "performer", "partner", "Torres Twin", "color cream", assim como diversas expressões depreciativas, com o intuito de se insultarem, nesse idioma. E, ainda, vários elementos culturais estrangeiros são citados ao longo da narrativa: Einstein on the beach, uma ópera do músico Philip Glass; romances policiais e westerns, respectivamente, de Ellery Queen e Frank Gruber; Paolo Buggiani, uma espécie de performer com o qual Leonardo desejava contracenar; Maria Callas, cantora de ópera, etc.

Dessa forma, já surge uma primeira característica dessa nova geração: esses jovens têm acesso a culturas distantes geograficamente, devido à globalização, e acabam identificando-se muito mais com os EUA ou com outros países estrangeiros do que com o próprio Portugal - característica de uma cultura pós-moderna, como ressalta Frederic Jameson (1989). E a situação do país luso é bastante especial e específica nesse contexto, uma vez que, como sentencia Boaventura de Sousa Santos (2011), Portugal é um país de desenvolvimento intermédio, que ficou para trás no processo de modernização do continente europeu. Assim, Miguel Real explica que o povo português transformou-se em uma espécie de cata-vento que gira de acordo com as brisas norte-americanas, que "[...] se submete a ventos internacionais dominantes, seguindo modas estrangeiras, incapaz de criar a sua própria personalidade" (REAL, 2012, p. 103); já Eduardo Lourenço (1982) chama a atenção para o fato de as soluções para os problemas portugueses serem invariavelmente procurados em um eterno "lá-fora" ou "lá-longe".

Seguindo os ventos do estrangeiro estão Leonardo, Paulina e Falcão. Os primeiros ambicionam morar em Nova York, visto que, em Portugal, segundo a mulher, tudo é mais atrasado, tudo é pior. Quando, por exemplo, ocorre um incêndio em um armazém próximo à casa da Arara, ela afirma que, se o acidente ocorresse "[...] em Manhatamm, jamais atingiria aquelas proporções. Lá os recursos deveriam ser adequados, e as ruas dimensionadas a uma boa escala permitiriam que os socorros chegassem com velocidade supersónica. 'Aqui, é tudo assim...'" (JORGE, 1995, p. 368). Na Big Apple, todos são felizes (ou, pelo menos, indiferentes), ao contrário da infelicidade geral portuguesa, completa ela.

Falcão, por sua vez, inicialmente também expressa o desejo de deixar seu país, porque, segundo o jovem, "Lisboa, mesmo a horas mortas, mesmo junto aos lugares maus, mesmo rente às pessoas de hábitos vis, raramente oferecia um bom objetcto de reportagem" (ibid., p. 34). Como ele deseja produzir um cinema a partir do real, a partir de imagens da vida concreta, o que Lisboa lhe apresenta não o satisfaz, por ser muito pacato, comum, rotineiro. Porém, a narradora lhe diz que espere, pois tudo poderia mudar:

Mas era preciso dizer-lhe que não desesperasse, que aguardasse como tantos aguardavam pelo dia em que as coisas acontecessem. Nesta cidadezinha encarrapitada à beira do Oceano, tudo chegava tarde, mas o intervalo ficava mais breve e nos atingia mais cedo. [...] Se esperasse, ele poderia assistir ao chegar do rumor do novo mundo. Cheirava-se nas ruas, sabia-se que em breve deveríamos ter os nossos criminosos de série, os nossos matadores triunfais, parqueando calmamente no meio das nossas praças, ou escondidos, de noite, na areia das nossas dunas (ibid., p. 64).

Para Falcão e seus amigos, a modernidade e o progresso estão íntima e distorcidamente ligados à violência dos grandes centros urbanos - como 
se tudo o que viesse dessas metrópoles globalizadas fosse bom e positivo, cabendo aos portugueses arcaicos e atrasados copiar o molde tal e qual, sem reflexão e pensamento crítico. Aceita-se tudo o que vem de fora como progresso benéfico de antemão.

Porém, do passado de seu próprio país (e do passado extremamente recente em termos históricos, uma vez que o fim da ditadura ocorrera em 1974 e a narrativa passa-se apenas 14 anos depois, em 1988), eles não sabem nada: "Afinal éramos jovens, não nos lembrávamos de nenhuma tragédia, não a víamos no horizonte, nem tínhamos nada a lamentar que não fosse recuperável" (ibid., p. 31).

Ao se descer um lance de escadas da Casa da Arara, no térreo, encontrase a família Santos, mais conhecida por Lanuit: Eduardo Santos e sua mulher, Julieta, além de dois filhos. Ao contrário dos habitantes do segundo andar, os do primeiro fazem questão de nunca esquecer: a própria alcunha pela qual Eduardo é conhecido, Lanuit, deve-se às torturas pelas quais o homem precisou passar durante a sua prisão na época do Salazarismo somente no período da noite - durante o dia, ele era deixado em paz. Por conseguinte, seu próprio nome não lhe permite deixar de lado o que lhe aconteceu, mesmo que sua mulher, Dona Juju, preferisse que assim não fosse:

Ah! Mas tudo isso aconteceu há muitos anos, há tantos anos que lembrá-lo nem faz bem, só vem atrapalhar a memória da pessoa. Morreu, o tempo levou essas noites em que sacrificaram Lanuit. Estou de acordo consigo. Deve-se pedir às pessoas que ainda se lembram, precisamente, que não se lembrem mais, para não nos atrapalharem a vida. Mas Lanuit, oh Lanuit tem uma memória fantástica (JORGE, 1995, p. 55).

O homem vive trancado em um galpão separado do resto da casa (completamente isolado, portanto), não trabalha, obrigando sua mulher a alugar os quartos a fim de sobreviverem, e passa os dias a escrever tabelas nas paredes e a pensar no projeto de um livro: o volume chama-se Alguém nos amará mais tarde; já as listas intitulam-se "Estes são os que não devemos esquecer", "Os que não podemos perdoar", "Os verdadeiros traidores" e "Aqueles que não nos traíram mas nos deixaram sós". Portanto, surge o retrato de um homem ressentido que não conseguiu acompanhar o ritmo da evolução do tempo e que não se conformou com o fato de os seus atos, tão importantes para o surgimento de um Portugal democrático, terem sido negligenciados e esquecidos - e que ainda espera por esse reconhecimento, mesmo que em um futuro longínquo, o que fica visível no título da sua obra em gestação ${ }^{1}$. A mulher, por sua vez, anseia por um marido bem ajustado a uma sociedade de progresso, de modernidade e de consumo e passa as tardes provando roupas caras pelas quais não pode pagar - pelo menos não no presente ou com Eduardo passando os dias simplesmente a lembrar.

Porém, como o que inicialmente interessa à narradora são os moradores do primeiro andar, "porque ali o mundo era outro, diferente, sem campânulas, mais perto das estrelas, do céu e da totalidade" (JORGE, 1995, p. 28), o foco recairá, principalmente, sobre eles. Dos seis jovens, dois destacam-se: Leonardo, o Static Man, o garoto que ambiciona ficar completamente imóvel por horas e horas, e Falcão, aspirante a cineasta de um tipo de cinema cru, real, documental - o "Cinema Direto", como ele chama.

Primeiro, Leonardo, com a ajuda de Paulina, segue os preceitos da obra Bio Feedback Training, a fim de executar exercícios de relaxamento e dietas para atingir a imobilidade completa durante horas e horas. E é justamente esse termo, "imobilidade", que Santos (2011) utiliza para pensar sobre a situação portuguesa durante e depois do Salazarismo: o

1 Tanto a ideia para o livro quanto as listas da parede ecoam em outro romance da mesma autora, $O$ memoráveis, de 2014: no enredo, a narradora e dois amigos entrevistam várias das figuras que fizeram parte da Revolução dos Cravos a fim de produzirom um dosum

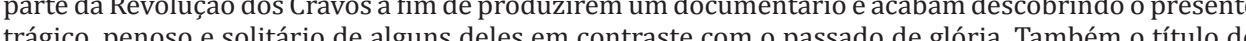
volume é bastante significativo, pois o fato de a participação desses sujeitos caracterizar-se co do memorável para a história de Portugal não faz deles sujeitos memorados na atualidade. 
sociólogo explica que, se no período salazarista, a mudança não era vista com bons olhos e a imobilidade era valorizada, pelo contrário, depois do fim da ditadura, a sociedade nega e desvaloriza esse mesmo imobilismo. Contudo, o teórico questiona-se se tal assunto pode realmente ser tratado dessa forma simplista e redutora: Santos pergunta, visto que ele considera que, no primeiro tempo, a mudança ocorreu sob a forma de imobilismo, se, no segundo tempo, o imobilismo pode estar se apresentando sob a forma de mudança. Portanto, esse personagem de Lídia Jorge pode representar um Portugal que, mesmo entrando para a União Europeia, em 1986, mesmo pegando dinheiro emprestado para, por exemplo, modernizar sua capital, mesmo acreditando estar cada vez mais atual, está imóvel, parado no tempo; uma pátria renovada em sua aparência, em seu exterior, mas imóvel em termos ideológicos, já que a liberdade desobrigou o povo de lutar por e de pensar sobre seu país e suas necessidades.

E ainda se pode pensar em qual a motivação para tal praticamente inumana meta. Apesar de Paulina procurar conferir objetivos concretos para a empreitada, como conseguir dinheiro para irem para Nova York (cidade onde tudo acontece, ao contrário de Portugal) ou bater o record da imobilidade voluntária, Leonardo apenas deseja fazê-lo para sua própria satisfação:

Pois voltava a estar ali apenas para estar, para se encontrar com seu $E u$ espalhável pelo Universo. 0 que ele queria era mostrar como uma pessoa domina o movimento e o tempo, mais nada, se isso era alguma coisa. Essa coisa, essa ideia para a qual ele não tinha outra palavra senão Nada, era a sua honra (JORGE, 1995, p. 327).

Ademais, o garoto produz uma faixa na qual expressa todo o seu não engajamento: "Por nada e por ninguém - Todos somos o nada que é tudo" - e, em relação a Portugal, Santos fala sobre a constante "ausência-de-projeto- feita-projeto-em-si-mesma" (2011, p. 53) da história desse povo, desde a era do início das grandes navegações: os portugueses, por exemplo, parecem ter desbravado e conquistado novos mundos apenas pelo espírito de aventura, sem a preocupação com um plano efetivo de ocupação e de desenvolvimento de suas colônias, seguindo um improviso puro - assim como Leonardo, que se desgasta com o imenso esforço para se manter imóvel sem ter um plano no qual essa imobilidade se encaixe.

Essa falta de uma perspectiva, de um objetivo mais concreto, incomoda muito algumas pessoas, como o próprio Eduardo Lanuit, que, quando o enxerga fazendo suas performances de imobilidade na rua, sente-se ofendido e pede à mulher que o expulse da Casa da Arara:

Aquela pessoa a quem por acaso sua mulher dava guarida encontrava-se a fazer troça de si e de todos aqueles que uns anos atrás tinham feito Estátua nas enxovias da polícia por protegerem vidas, defenderem ideias, arvorarem no alto as sagradas bandeiras da utopia. Eles tinham ficado horas e horas sofrendo, em pé, afastados das paredes e de braços estendidos como cristos, agonizando pelos objectos altos da humanidade. Agora era o oposto. Ali estava aquele palhaço treinando-se para nada, absolutamente nada, que no dizer do seu cartaz era o seu tudo! (JORGE, 1995, p. 244)

Portanto, aqui surge, mais uma vez, a oposição entre as duas gerações dos diferentes níveis da casa da Arara: uma que não se lembra de nada, outra que lembra de tudo; uma sem grandes lutas e ideais, a não ser os pessoais, os individuais e outra que lutou pelo bem comum - porém, apesar da contradição entre os moradores do primeiro e segundo andar, Julieta Lanuit explica para a narradora como Leonardo e seu marido são, na verdade, muito semelhantes em sua resistência: "O mesmo físico, a mesma resistência, o mesmo anseio de alterar a caminhada dos outros, a mesma vontade inquebrantável de fazer parar, fazer reflectir, o mesmíssimo desejo de dar a vida por uma causa" (ibid., p. 53). Assim, é possível afirmar que o 
velho e o jovem são ambos capazes de resistir, de lutar - o que os diferencia é a motivação para essa resistência e a intensidade da relação entre esses atos obstinados e a história, a situação social, econômica ou política da sociedade em que eles estão inseridos.

Já Falcão, o aspirante a "Orson Welles", começa a descobrir em Lisboa sinais do que ele acredita ser a modernidade: serial e mass killers, modalidades de assassinos aos quais os lisboetas não estavam acostumados - "entre nós não se noticia a acção dum mass killer que acaba de aparecer. Ninguém ainda sabe lidar com essas figuras" (JORGE, p. 128). Tanto ele, quanto Paulina, que o ajuda de forma mais direta, e os outros companheiros do segundo andar, não parecem se importar com as pessoas que foram ou que podem ser assassinadas por esses novos tipos de criminosos, mas apenas com a realização da sua arte e com a filmagem das vítimas ou, até mesmo, do assassino em ação. Culpa, receio, empatia para com aqueles que sofrem são sentimentos dos quais raramente eles se ocupam - e, caso se ocupem, acabam por descartá-los rapidamente, uma vez que consideram o filme-reportagem de Falcão como mais importante do qualquer vida.

Em relação a essa frieza, uma cena na qual Julieta Lanuit tenta suicidarse e é encontrada inconsciente por Falcão e Paulina é bastante ilustrativa, pois, ao se depararem com a visão da mulher nua em cima da mesa da sala de jantar, os dois correm com as câmeras: "Tornava-se necessário fixar-lhe o rosto, as mãos, os pés, fazer um grande plano de perfil, um plano iluminado. Rápido, rápido e bem, pois, infelizmente, já alguém estava a chamar por Eduardo Lanuit" (JORGE, 1995, p. 251, grifo meu). 0 impulso dos dois garotos é o de fazer arte com a desgraça do outro, e não o de auxiliá-lo.

Também quando Leonardo acaba morrendo durante uma perfomance (talvez pela dieta extremamente restrita a que se submetia e que o deixara muito magro, talvez pela exigência e pelo esforço de ficar horas e horas imóvel, talvez pela soma de tudo isso), Falcão sente-se extasiado com a cena do Static Man caindo de seu "plinto" e, ao invés de correr para acudir o amigo, sua primeira reação, quase instintiva, natural, é, mais uma vez, filmálo: "Falcão achou belíssimo o que via, e continuou a captar imagens, atrás de imagens, pois Leonardo, quando chegou ao chão, deu um solavanco rápido e virou o corpo na direcção das janelas. Só que, de repente, não se movia mais" (ibid., p. 374).

Entretanto, não é apenas Paulina e Falcão que manifestam tal falta de responsabilização pelos fatos que acontecem ao seu redor: Osvaldo, César e Susana Marina (moça que admira e segue Leonardo) morrem sem que um grande sentimento de pesar por parte dos demais seja percebido, mesmo que os últimos possam ser considerados como indiretamente culpados por esses precoces falecimentos. O primeiro a expirar é Osvaldo, que é incitado por Falcão, Leonardo, César, Gamito, Paulina e pela própria narradora a buscar na sua antiga casa umas blusas com os dizeres "Muerte a los Estúpidos". Porém, o personagem possuía problemas com drogas e havia vendido todos os móveis (com exceção de um feito de sólido carvalho impossível de desmontar) para tentar saldar suas dívidas e estava visivelmente com medo de voltar ao velho lar. Mesmo assim, os jovens insistiram que ele deveria ir a fim de "ultrapassar esse complexo" (JORGE, 1995, p. 79), de "mostrar aos gangsters que se tinha tornado impenetrável" (ibid., p. 79) e de parar de "fugir de si mesmo" (ibid., p. 80). Porém, Osvaldo nunca retorna à casa da Arara e seus companheiros só percebem a sua falta, porque, alguns dias depois, Gamito precisara de uma pastilha vendida pelo companheiro. Descobrem que o garoto havia sido assassinado pelas pessoas a quem ele devia dinheiro, mas chegam à conclusão de que não devem se sentir culpados:

A realidade era esta - Eles tinham mandado Osvaldo lá a casa, contra a vontade do próprio. Mas deveriam agora envolver-se num processo de culpa? Não, não deviam. Alguma vez o rapaz que só lia jornais do dia anterior, e buscava empregos com vinte e quatro horas de atraso, teria de enfrentar a dificuldade, 
passar o cerco em que se encontrava envolvido. Eles até o tinham mandado na melhor hora, a hora da madrugada. Que culpa tinham? Absolutamente nenhuma (ibid., p. 98)

Já César morre em decorrência de uma doença, após ser expulso da Casa da Arara pelos outros, devido ao medo de seu mal ser contagioso; Susana, de uma tênia que ela engoliu a fim de emagrecer, seguindo o exemplo de "força" e "determinação" de Leonardo. Além disso, a narradora, apesar de se declarar inocente e isenta de tudo o que aconteceu ao longo da narrativa, é quem dá a ideia da tentativa de suicídio a Julieta através de seus esquemas na parede que funcionavam como previsões para cada um dos moradores da casa. Dona Juju, ao se deparar com o que estava escrito sobre si mesma, fala:

Às vezes arrependo-me do que conto. Dum modo ou de outro, fica tudo gravado nesta parede. Mas desta vez, não corresponde à verdade, não estou desiludida. [...] Aí está como eu nunca irei ficar estendida sobre essa mesa. Porque lhe passou pela cabeça que me estenderia sobre uma mesa de cozinha? Sou uma pessoa pouco instruída mas tenho resistência. A sua previsão sempre me divertiu. Agora, para falar a verdade, ofende-me! (ibid., p. 232)

Apesar de declarar ter achado um absurdo a cena prevista pela narradora, a mulher de Lanuit acaba por cumpri-la - e talvez nunca a tivesse, caso o esquema não lhe houvesse apontado essa alternativa, já que, como a própria Julieta afirma, ela é uma pessoa de pouca cultura e imaginação.

Claro que não se pode considerar aqueles que ficaram como os culpados diretos pelos falecimentos - nenhum deles puxou o gatilho da arma que assassinou Osvaldo, nem forçou Susana a engolir o verme a fim de emagrecer ou contaminou César de propósito. Porém, levando-se em conta que eles estimularam as ações que levaram à morte dos outros e/ou que os abandonaram no momento em que os amigos mais precisaram de apoio, é possível pensar em uma culpa indireta - ou, pelo menos, em uma estranha e doentia indiferença em relação ao sofrimento de pessoas tão próximas a eles. Mas nada disso abala os amigos e sua confiança no que faziam: a culpa é sempre dos outros, sempre está fora. Mais uma vez, surge a oposição entre essa nova geração sem qualquer peso de responsabilidades nas costas e a geração anterior, de Lanuit, com responsabilidades demais, pois se sacrificaram realizando uma revolução em prol de todo um povo.

Se esse individualismo, impessoalidade, essa liberação de qualquer tipo de sentimento e também essa falta de preocupação com o coletivo ou com o próximo são sintomas do mundo pós-moderno, como aponta Frederic Jameson (1989), Portugal pode ser pensado como um caso especial, uma vez que a ditadura, nesse país, foi muito mais longa e perdurou enquanto os demais países, já democráticos ${ }^{2}$, começavam a evidenciar sinais dessa nova forma de ser no e de ver o mundo. Se, ao longo do salazarismo, apenas um discurso (o oficial) era permitido e todos, portanto, deveriam pensar, viver e escolher sempre coletivamente; se, durante a Revolução dos Cravos, o povo igualmente precisou unir-se para, em conjunto, derrubar um longevo governo, após esses momentos, nasce um forte desejo isolacionista. Como consequência, surge um povo que não é mais capaz de se pensar coletivamente, visto que existem outras prioridades - prioridades sempre individualistas. Como esclarece Lourenço, o povo português estava vivendo "sob o modo de um desenraizamento histórico singular" (LOURENÇO, 1982, p. 77). De tal modo, o romance de Lídia Jorge apresenta personagens que não se guiam por objetivos maiores do que as suas próprias vidas; que estão preocupados apenas com aquilo que desejam fazer, mesmo passando por cima de outras pessoas; que, a todo o tempo, isentam-se da culpa de seus atos e que ignoram sua própria história enquanto coletividade.

O nazismo na Alemanha acabou em 1945. o fascismo italiano, em 1943. Apenas o franquismo, assim como o salazarismo, durou até a metade dos anos 1970. 
Assim como o passado de Portugal não tem espaço nas preocupações dos habitantes do segundo andar da Casa da Arara, a própria história pregressa dos companheiros também não lhes interessa: eles haviam, inclusive, combinado de não contarem uns aos outros sobre o que lhes acontecera antes de se conhecerem. Porém, Gamito sugere aos amigos que cada um selecione um evento de seus passados: "cada um podia fazer apenas uma pequena demonstração para se conhecerem melhor, e depois fechariam logo as casinhas parvas donde tinham vindo" (JORGE, 1995, p. 75). Então Osvaldo conta sobre como ele e o irmão venderam todos os móveis da casa onde viviam a fim de sustentar o vício em drogas e sobre como o segundo faleceu. Ao término de seu relato, Paulina repreende-o: "Bolas, Al Pacino, que coisa mais triste! Quem vai hoje conseguir adormecer? Não podias ter contado outra passagem da tua vida?" (ibid., p. 78). Portanto, se pensarmos que a casa da Arara é o microcosmo do macrocosmo Portugal, surge mais uma motivação para esse esquecimento voluntário do passado recente do país: deixar de lado a dor dos desaparecimentos, mortes, torturas, censura e do medo constante de falar, opinar, agir durante os anos de ditadura; esquecer que um dia os portugueses sofreram.

Todos esses jovens, Leonardo, Falcão, Paulina, César, Gamito e Osvaldo, desejam ser livres - livres de responsabilidades, de culpas, de expectativas, dos pais. Surge, portanto, mais uma característica a uni-los: ao longo da narrativa, o leitor descobre que todos vêm de estirpes muito ricas - quando, por exemplo, um policial interrompe a apresentação do Static Man e pede pelos documentos do garoto, ele fica bastante intrigado, quando descobre que, além de rica, a família é bastante importante e influente: "Que raio faz você aqui, feito palhaço, você, filho de gente conhecida? Você deveria levar mas é um puxãozinho de orelhas" (ibid., p. 113). E mais do que isso: os parentes dos alugadores dos quartos do segundo andar da Casa da
Arara, além de abastados e proeminentes, são dominantes e autoritários. A fim de fugirem do jugo familiar, os jovens saem de casa e vivem em um imóvel a ponto de ser demolido - porém, em várias situações, algum deles levanta a hipótese de pedirem dinheiro aos progenitores, como quando se decide que Leonardo tentará bater o record e Gamito e Osvaldo sonham poder largar seus empregos (em um salão de beleza e em um restaurante, respectivamente) para poderem acompanhar e auxiliar o atleta. Contudo, logo eles chegam à conclusão de que não vale a pena a independência econômica em troca da dependência em todos os outros sentidos das suas vidas:

Mas César, que poderia socorrer-se desse estratagema, não queria arriscar metendo no caso pessoas da família. Até parecia que se estava a voltar atrás. Para que tinham lutado para serem independentes do passado que os agarrava aos locais tenebrosos donde haviam partido? [...] Ele, César, submetia-se a um emprego cujo barrete em forma de sexo lhe apertava a cabeça, ficando com vinco de chui, precisamente para ser livre. Todos ali faziam o mesmo (ibid., p. 166).

Esses pais extremamente impositivos em relação a seus filhos lembram Salazar, que se autoproclamava o "paizinho" de Portugal e dos portugueses, mas que era um pai ditador e controlador de seu povo. Somado a isso, como explica Jorge Babo (1991), a crise econômica agravada após a I Guerra Mundial e os obstáculos criados para a obtenção de empréstimos no estrangeiro, além de uma enorme incerteza em relação ao futuro e um medo de o país ser visto como um exemplo de decadência, foram alguns dos motivos para que Salazar, o ministro das Finanças, chegasse ao poder. Dessa forma, surgiu em torno da figura do estadista o mito da "'genialidade' do 'salvador da pátria', 'regenerador das Finanças', 'restaurador da dignidade ofendida do país', transformado, por encanto, de 'mendigo internacional' em 'respeitável membro da Comunidade" (BABO, 1991, p. 212). Entretanto, se 
o problema financeiro foi ou parecia ter sido resolvido, o que Salazar pediu em troca de tal solução foi a liberdade dos portugueses, como esclarece Fernando Pessoa:

Chegámos a isto, Senhor Presidente: passou a época da desordem e da má administração; temos boa administração e ordem. E não há nenhum de nós que não tenha saudades da desordem e da má administração. Não sabíamos que a ordem nas ruas, que as estradas, as pontes e as esquadras tinham que ser compradas por tão alto preço - o da venda a retalho da alma portuguesa (PESSOA, 1993, p. 233).

Assim como Salazar em relação a Portugal, os pais dos jovens da casa da Arara representariam o fim de seus problemas financeiros - porém, todos receiam pedir por essa ajuda monetária e acabar voltando ao jugo familiar; todos prezam por sua liberdade, mesmo que essa liberdade seja utilizada para executar ações desprovidas de sentido, de consequências positivas para os próprios envolvidos e para os demais. Portanto, em Portugal, ao longo de mais de quatro décadas, o regime totalitarista cerceou a liberdade da população com a censura e a vigilância contínuas, envolvendo prisões arbitrárias, interrogatórios e inumanas torturas feitas pela Polícia Internacional e de Defesa do Estado (PIDE) - e esse macrocosmo é representado pelo microcosmo da relação dos jovens moradores da Casa da Arara com os seus pais, que continuamente limitaram a possibilidade de escolha e de livre pensamento da nova geração, que, por sua vez, acabou perdendo a noção do coletivo quando, finalmente, consegue se ver livre da opressão.

Sobre essa atmosfera de repressão da qual os personagens mais jovens desejam se libertar, é representativa e significativa a cena na qual o pai de Leonardo procura pelo filho, quando esse está no meio de uma de suas apresentações de imobilidade e tenta convencê-lo a voltar para casa prometendo-lhe liberdade:
0 teu lugar deveria ser no teu quarto. Agora, por exemplo, pegavas em ti $\mathrm{e}$ nas tuas coisas e voltavas para a tua casa. Tomavas o teu banho, deitavas-te na tua própria cama. Acordavas quando querias, comias quando te apetecias. Ninguém mais te iria dizer nada. [...] Volta para a tua casa como se não houvesse parentesco entre nós, regressa como um amigo (JORGE, 1995, p. 262,263).

Mesmo essas promessas já dão os indícios de como era a vida de Leonardo antes: com horários para tudo, com a presença forte dos progenitores controlando e interferindo. Porém, não é apenas nisso a que tal controle fica restrito: ao longo do discurso do patriarca, surgem evidências de uma cobrança e de uma vigilância exacerbadas, pois, em diversos momentos, o homem fala sobre o fato de os irmãos de Leonardo sempre terem conseguido os primeiros lugares em tudo o que faziam, assim como os seus pais, que também foram invariavelmente muito bons naquilo em que se empenharam. Sobre uma das irmãs, que precisou de tratamento psiquiátrico por não ter correspondido às expectativas familiares, ele esclarece: "Para ser exacto, a tua irmã Candi ficou em segundo lugar, por injustiça daquela cambada do Técnico. Naturalmente que não foi por ficar em segundo lugar que ela se pôs depressiva, foi pela injustiça. Está a tomar uns comprimidos" (JORGE, 1995, p. 265) - o que evidencia a pressão exercida sobre a jovem, que ficou arrasada com um resultado muito bom, mas que ainda estava aquém das suas expectativas. Ele também se refere a uma professora da infância de Leonardo que gritava com o menino e acusava-o de não ter talento e do medo do jovem de passar pela biblioteca do pai - sempre, é claro, se comprometendo a não obrigar o filho a passar pelas mesmas situações traumáticas. Por fim, ele reconhece o valor do rebento procedente da vontade do garoto de bater o record mundial:

Mas agora, meu filho, tu, passado este tempo, mostras o que vales - Também tu queres ser o primeiro. Queres ser o primeiro na tua disciplina. Aceito. Os teus irmãos aceitam, a tua mãe aceita. Não quer dizer que a disciplina que praticas 
eu a ache muito relevante, mas o que importa é que nessa disciplina, relevante ou não, tu queres ser o primeiro, à frente do primeiro. E isso é interessante. Na verdade, tu não queres ser nem o terceiro nem o segundo, tu queres atingir o melhor lugar do mundo. Poderia ser em Direito ou em Ciência, mas não faz mal, se é em imobilidade voluntária que tu queres, aceitamos (ibid., p. 364).

Portanto, mesmo tentando assumir um discurso de tolerância, de respeito, de aceitação, em diversos momentos da fala do progenitor, surge, mais uma vez, a cobrança e a imposição de um modelo de vida, de conduta: o pai, por exemplo, até aceita a escolha inusitada do filho, mesmo que ela não seja condizente com o que é considerado sério e útil pela sociedade, porque o menino dispôs-se a ser o melhor na sua categoria - também no regime salazarista todos deveriam pensar e agir conforme os mesmos princípios, que eram os oficiais.

Temos, assim, o seguinte cenário no Portugal pós-25 de abril: alguns, no passado, lutaram para que os do presente pudessem agir da forma como quisessem, porque tudo no mundo passaria a ser permitido, desde que estivesse conforme o gosto, o anseio e o prazer de quem age; alguns lutaram para que outros vivessem em um mundo simples onde tudo é natural e sem mistérios; lutaram para que aqueles que viessem a seguir não precisassem se preocupar em apenas se preocupar em construir um mundo livre, pois, como o mundo já seria livre, eles igualmente estariam libertos para desejarem, sentirem, fazerem, preocuparem-se com apenas aquilo que quisessem. $\mathrm{Ou}$ por outras palavras - Paulina, Falcão, Osvaldo, César, Gamito, Leonardo e a narradora de 0 jardim sem limites não sabem o que foi a ditadura de Salazar ou a Revolução de Abril, não se sentem em dívida para com aqueles que lutaram pelo fim da ditadura, não querem saber de nenhum passado, de nenhuma história que lhes traga dor - e isso apenas porque Eduardo Lanuit (e outros como ele) sacrificou toda uma fase da vida, sua integridade física e psicológica para que os jovens da nova geração pudessem escolher entre se preocupar ou não se preocupar, entre saber ou não saber, entre se engajar ou não se engajar.

\section{Referências}

BABO, Jorge. A tragédia portuguesa: dos mitos às realidades. Lisboa: Editora Ulisseia 1991.

JAMESON, Frederic. El debate modernidad-Posmodernidad. Buenos Aires: Puntosur, 1989. JORGE, Lídia. O jardim sem limites. Lisboa: Publicações Dom Quixote, 1995.

Os memoráveis. Lisboa: Publicações Dom Quixote, 2014.

LOURENÇO, Eduardo. O labirinto da saudade. Lisboa: Publicações Dom Quixote, 1982

PESSOA, Fernando. Pessoa inédito. Lisboa: Livros Horizonte, 1993. Disponível em: http://arquivopessoa.net/textos/1753. Acesso em: 16 nov. 2014.

REAL, Miguel. A vocação histórica de Portugal. Lisboa: Esfera do Caos, 2012.

SANTOS, Boaventura de Sousa. Portugal: ensaios contra a autoflagelação. São Paulo: Cortez, 2011.

SENA, Jorge de. Carta aos meus filhos sobre os fuzilamentos de Goya. Disponível em: http://www.lerjorgedesena.letras.ufrj.br/antologias/poesia/alguns-poemas-politicos/. Acesso em: 16 nov. 2014.

Recebido em 07/11/2015

Aceito em 04/01/2016. 